\title{
Why-questions, topicality and intervention effects in Chinese
}

\author{
Dawei Jin \\ SUNY Buffalo \\ daweijin@buffalo.edu
}

\begin{abstract}
This paper revisits intervention effects in Mandarin Chinese why-questions. I present new data showing that the ability for quantifiers to induce intervention hinges upon their monotonicity and their ability to be interpreted as topics. I then develop a semantic account that correlates topicality with monotone properties. Furthermore, I propose that why-questions in Chinese are idiosyncratic in that why directly merges at a high scope position that stays above a propositional argument. Combining the semantic idiosyncrasies of why-questions with the wide scope behaviors of topicality, I conclude that my account explains a wide range of intervention phenomena in terms of interpretation failure.
\end{abstract}

Keywords: intervention effects; why-questions; illocutionary acts; wide-scope indefinites; Mandarin Chinese.

\section{Data}

This paper presents a semantic account of the intervention effects in Mandarin Chinese why-questions. By intervention effects, I refer to the unacceptability caused when scope-taking elements c-command an interrogative phrase. (1) schematizes the intervention induced in in situ wh-questions when an in situ wh-phrase is c-commanded by a quantifier.

$$
\text { \#[Q [Quant wh] }]
$$

\footnotetext{
* Acknowledgements: I would like to thank Jean-Pierre Koenig, Matthew Dryer and Rui Chaves for their comments. I am also grateful to the two anonymous reviewers of YPLM for their very helpful feedback. I am deeply indebted to Jun Chen and Lihua Xu for supplying their judgments. Needless to say, all the remaining errors are my own.
} 
Using Chinese data, this paper argues that the intervention induced by whyquestions is distinct from other intervention effects that arise in non-why interrogative questions. Apart from why-questions, intervention effects are also identified in non-why Chinese wh-questions where in situ wh-phrases are ccommanded by focus-sensitive expressions such as only-NPs and even-NPs. ${ }^{1}$

$$
\begin{aligned}
& \text { \#Zhiyou Lisi chi-le shenme? } \\
& \text { only Lisi eat-PRF what } \\
& \text { 'What has only Lisi eaten?' }
\end{aligned}
$$

$$
\begin{aligned}
& \text { \#Lian Lisi ye chi-le shenme? } \\
& \text { even Lisi PRT eat-PRF what } \\
& \text { 'What has even Lisi eaten?' }
\end{aligned}
$$

The present paper is built upon the assumption that such intervention is distinct from the intervention induced in Chinese why-questions. That is, these two phenomena are not characterized by a uniform mechanism. I further believe that the semantic account of focus-induced intervention by Beck (2006) promises to explain the examples in (2). In other words, my current proposal deals with a separate set of data from Beck's, and should not be viewed as an alternative (but rather a supplement) to her theory.

Importantly, I present new data showing that intervention effects in Chinese $w h y$-questions are unique in that they are sensitive to the type of quantifier. As (3) shows, when weishenme 'why' is c-commanded by a monotone decreasing quantificational DP, oddness ensues.

$$
\begin{array}{lll}
\#\{\text { Meiyou } & \text { ren/henshao ren }\} & \text { weishenme cizhi? } \\
\text { no } & \text { person/few person }\} & \text { why r resign } \\
\# \text { 'For }\{\text { nobody/few people }\} \text {, why did they resign?' }
\end{array}
$$

In contrast, a quantificational DP with a simplex monotone increasing determiner, such as most people or a few people, does not induce intervention effects. $^{2}$

\footnotetext{
${ }^{1}$ The glossing in this paper follows the Leipzig Glossing Rules (LGR).

${ }^{2}$ A monotone increasing quantifier, such as most, is "monotone increasing" because when the predicate in the body of the quantified expression is made less restrictive, the truth value is preserved (Westerståhl 2015). Thus,
} 


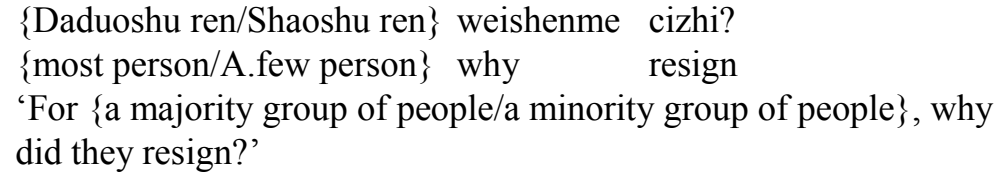

To make things more complex, one class of monotone increasing quantificational DPs with morphosyntactically complex determiners induce weak intervention. This class includes modified numerals such as at least three people, more than three people, etc. Non-monotonic bare numerals, such as three people, also induce weak intervention. An example is given in (5). When uttered out of the blue, members of this class often trigger rather low judgments for some speakers, while for other speakers the oddness is less severe than that which is induced in monotone decreasing contexts.

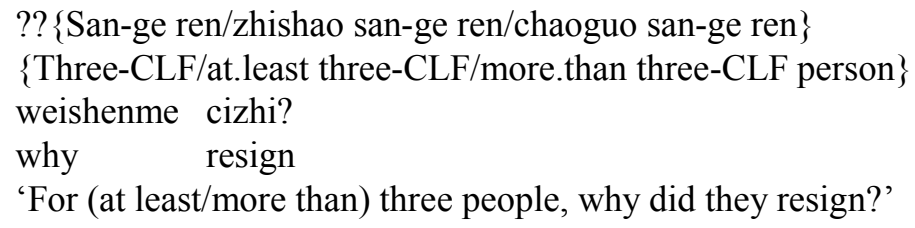

So far, I have only discussed matrix why-questions. In an embedded whyquestion, morphosyntactically simplex monotone increasing quantifiers still induce no intervention, as shown by the perfectly acceptable sentence in (6).

(6) Wo yijing zhidao-le \{daduoshu ren/shaoshu ren\}

I already know-PRF \{most person/a.few person\}

weishenme cizhi.

why resign

'I already knew, for \{a majority/a minority group of people\}, why they resigned.'

(i) Most men work hard.

entails

(ii) Most men work.

Alternatively, this is called "right upward monotone" in the literature. By contrast, for monotone decreasing quantifiers, when the predicate in the body of the quantified expression is made less restrictive, the truth value is not necessarily preserved. Quite the opposite, it is preserved when the body is made more restrictive.

(iii) Few men work.

entails

(iv) Few men work hard. 
More noteworthy is the fact that the weak intervention we witness in (5) disappears in embedded why-questions. This is demonstrated by the acceptability of (7).

(7) Wo yijing zhidao-le \{san-ge ren/zhishao san-ge ren/

I already know-PRF \{three-CLF person/at.least three-CLF person/ chaoguo san-ge ren $\} \quad$ weishenme cizhi.

more.than three-CLF person \} why resign

'I already knew, for a group of (at least/more than) three people, why they resigned.'

By comparison, intervention cannot be circumvented in embedded contexts for monotone decreasing quantifiers. As (8) illustrates, the unacceptability in an embedded why-question is as strong as it is in a matrix one.

(8) \#Wo yijing zhidao-le \{meiyou ren/henshao ren $\}$ weishenme cizhi.

I already know-PRF \{no person/few person\} why resign

\#'I already knew, for \{nobody/few people\}, why they resigned.'

In sum, intervention effects in Chinese weishenme-questions are sensitive to quantifier monotonicity. In addition, they are sensitive to whether weishen$m e$-questions occur in matrix or embedded contexts. The overall pattern is summarized in (9).

(9) In matrix and embedded weishenme-questions:

(i) Monotone decreasing quantifiers consistently induce intervention effects;

(ii) Monotone increasing, non-numeral quantifiers do not induce intervention effects;

(iii) (Monotone increasing) modified numerals and (non-monotonic) bare numerals induce weak intervention in matrix why-questions, which is ameliorated under embedded contexts.

Apart from quantificational DPs, adverbs of quantification exhibit similar patterns. (10) illustrates the failure for monotone decreasing quantificational adverbs to c-command weishenme 'why'. 
(10a) \#Ta congbu weishenme cizhi?

he never why resign

\#'On no occasions, why did he resign?'

(10b) \#Ta henshao weishenme cizhi?

he seldom why resign

\#'On few occasions, why did he resign?'

Furthermore, this ban on c-commanding quantificational adverbs is lifted if the adverbs are monotone increasing or non-monotonic, as in (11).

(11a) Ni dabufen shijian weishenme juede kun?

you most time why feel be.drowsy

'For most of the occasions, why did you feel drowsy?'

(11b) Wo yijing zhidao-le ta zhishao liang-ci

I already know-PRF he at.least two-token

weishenme bu-gan zuo zhei-jian shi.

why NEG-dare.to do DEM-CLF affair

'I already knew, for at least two occasions, why he wouldn't dare to do that.'

The following example demonstrates that focus-sensitive phrases also induce intervention effects in weishenme-questions. Sentence (12a) is unacceptable, because weishenme is c-commanded by the focus-sensitive only-NP. (12b) is similarly unacceptable, when weishenme is c-commanded by the focus-sensitive operator lian ...ye. ${ }^{3}$

\footnotetext{
${ }^{3}$ In Chinese, zhiyou 'only' forms a constituent with an NP and assigns focus value to the NP. The lian + NP + ye/dou construction is often assumed to be the Chinese counterpart of the English focus-sensitive even-NP (Shyu 1995; Hole 2004). It seems that lian and ye/dou together contribute to the semantics of the English focus particle even, although the exact nature of the division of labor is still not clear. According to some analysis, lian assigns focus accent to the $\mathrm{NP}$ it combines with, and the maximality operator $d o u$ in this context is argued to overtly express the alternatives in the focus value (Giannakidou and Cheng 2006; Badan 2008).
} 
(12b) \#Lian Lisi ye weishenme cizhi?

LIAN Lisi also why resign

\#'For even Lisi, why did he resign?'

In this paper, I propose to account for this complex array of data in terms of the idiosyncratic semantics of weishenme 'why'. In a nutshell, I argue that Chinese weishenme must be initially merged at the high scope position of [Spec, CP]. When quantifiers are interpreted as taking wide scope over [Spec, CP], we get coherent interpretations. On the other hand, intervention arises when certain quantifiers are unable to be interpreted at such high scope. Hence, this account of intervention effects in why-questions does not involve "real" intervention, in the sense that no mechanism of covert movement is assumed. Rather, my central claim in this paper is that the unacceptability we are dealing with here is not syntactic ill-formedness, but interpretational failure, i.e., a native speaker cannot assign an interpretation to a whyquestion in certain scopal relations. Consequently, I choose to put a \# sign before unacceptable Chinese why-question sentences as well as their English translations to indicate that such examples are odd because the readings they generate are semantically anomalous.

The rest of this paper is structured as follows. Section 2 provides a critical review of the previous minimalist-based theories of the Chinese intervention effects in why-questions. In Section 3, I discuss why's syntactic and semantic idiosyncrasies and argue that quantifiers are able to take wide scope over why when they receive a topical reading. Section 4 spells out a semantic account that explains the intervention pattern of Chinese why-questions in terms of quantifier topicality. Section 5 concludes the paper. Throughout the paper, the reported judgments of novel data are based on three native speakers of Mandarin Chinese (including myself).

\section{Previous theories}

In recent minimalist approaches, intervention effects in Chinese whyquestions have been argued to follow from the relativized minimality effect (Rizzi 1990; Rizzi 2001; Rizzi 2004) that arises during covert feature movement at LF. According to the relativized minimality approach, the quantificational "likeness" between a quantifier and the interrogative phrase weishenme means that weishenme is attracted to the left periphery scope position on- 
ly if it is closer to the scope position than the quantifier is. Yang (2011) borrows Starke's (2001) and Rizzi's (2004) recent formulations of relativized minimality and provides the following condition, in which the minimality effect is captured in terms of a filter, as in (13).

(13) Maximal Matching Filter (Yang 2011: 63)

Let $\mathrm{X}$ and $\mathrm{Y}$ be bundles of features in a sequence of [...X...Y...]; $\mathrm{Y}$ cannot cross $\mathrm{X}$ when $\mathrm{Y}$ is maximally matched by $\mathrm{X}$.

Figure 1 schematizes the Maximal Matching Filter.

(a)

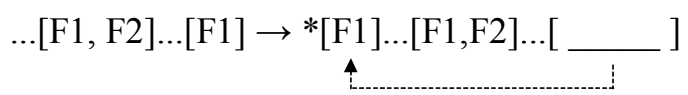

(b)

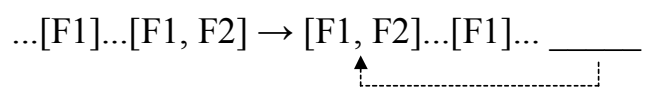

Figure 1. The Maximal Matching Filter.

If a scopal element $A$ bears feature [F1] and needs to move to its left periphery scope position, and if another scopal element $\mathrm{B}$ has the feature geometry that includes the bundle [F1 F2], then the movement of A from its initial merge position to its scope position is blocked because the bundle [F1 F2] maximally matches [F1]. In other words, the filter condition rules out the scope-taking of an operator at the left periphery when a "like" operator is closer to the scope position of the said operator.

The criteria of operator type matching are determined as follows (Rizzi 2004: 19):

(14a) Argumental: person, number, gender, case

(14b) Quantificational: Wh, quantifier, measure, focus...

(14c) Modifier: evaluative, epistemic, $\mathrm{Neg}$, frequentative, celerative, measure, manner, ...

(14d) Topic 
Based on this classification, quantifiers as well as focus-sensitive expressions (focus) possess the same quantificational feature as the interrogative operator (Wh). Apart from the quantificational feature, quantifier/focus also bear other features. In a [Quant/Focus $<\mathrm{Wh}$ ] configuration, the maximal matching filter is violated during covert feature movement, because the quantificational feature is maximally matched by the intervening quantifier/focus.

The minimality approach enables a unified account of intervention effects in both quantifier-induced and focus-induced contexts. However, this approach is problematic upon closer scrutiny. This is because the minimality approach treats all quantifiers as legitimate interveners that block the LF movement of an interrogative operator. Quantifiers are interveners, simply because they bear a quantificational feature. Therefore, such approach would not predict the Chinese intervention pattern in why-questions, where the intervention is sensitive to the type of quantifier (monotone non-decreasing versus monotone decreasing). Instead, this approach as it stands should predict that a finer distinction within quantifier type won't make any difference in intervention. If quantifiers in general possess enough features to maximally match the interrogative operator, then by including monotonicity as a further dimension in the feature geometry we only increase the inventory of the feature set for the quantifiers. Therefore, both monotone increasing and decreasing quantifiers are supposed to maximally match the interrogative operator and block its covert movement. Conceivably, we can modify the feature geometry so as to make monotonicity the only relevant feature in maximal matching. However, this would be rather stipulative, especially given that we find no independent evidence that monotonicity plays a role in other intervention environments in Chinese (i.e., those involving non-why constituent questions). Given the lack of well-motivated apparatus to allow only a subset of quantifiers to block covert LF movement, it seems that the validity of a minimality account is in question.

Finally, in embedded questions, a minimality account predicts that the covert interrogative operator still moves to take the embedded [Spec, $\mathrm{CP}$ ] scope position (crossing the quantificational interveners along the way). Hence, even assuming that quantifier types can be fine-tuned to accommodate the intervention data in matrix questions that we have seen in (3-5), (10-11) and (12), it is mysterious how a minimality account handles the selective amelioration phenomenon in the embedded questions of (6-8) in a principled manner. 


\section{The scopal behaviors of weishenme 'why' and topics}

\subsection{The syntax and semantics of weishenme 'why'}

It has long been noticed that the why-adjunct behaves in a different way from other $w h$-phrases. As early as Lawler (1971), it has been proposed that, in a why-question, why is not associated with any variables in the clause that it attaches to. The no-trace property of why is demonsrated in (15). As Lawler points out, only one reading is available in the following quantificational environment:

(15) Why did three men leave?

Reading A: 'Why is it the case that three men left?'

Reading B: \#'What reason ${ }_{i}$ did three men have $t_{i}$ for leaving?'

In reading $\mathrm{A}$, an event, three men left, is presupposed. By wondering why this event occurs, we are committed to a situation in which the total number of people that left has to be three. In reading B, it is also the case that a group of three individuals left. Yet there is no requirement that, in this situation, $a l$ together three people left. There could be other individuals who left, but for some reason the speaker is only concerned with a specific group of three people. When it happens that only three people left in the context, the two readings are not distinguishable. Crucially, however, when the context contains more than three individuals who have left, the why-question in (15) cannot be uttered, at least according to the speakers Lawler consulted.

If why binds a trace, the underlying structure of (15) would be (16). It would then be mysterious what rules out reading B, since there is no good reason to explain what causes three men to be interveners in a fronted whyquestion, but not in other fronted $w h$-questions.

$\mathrm{Why}_{\mathrm{i}}$ did three men leave why ?

It has been noticed that a similar situation happens in embedded contexts. This can be exemplified by the example in (17) (Cattell 1978; Oshima 2007).

(17) Why did you regret that Dr. Graff left the academia?

Reading A: 'What reason caused you to regret the fact that Dr. Graff left the academia?' 
Reading B: \#'What reason $n_{i}$ did you regret that Dr. Graff have $t_{i}$ for leaving the academia?'

In (17), why cannot be associated with the embedded clause, and can only be associated with the matrix clause. Again, this would follow if why does not move and hence does not leave behind a trace.

Furthermore, Tomioka (2009) demonstrates that, in downward entailing environments, why triggers different presuppositions from other $w h$-phrases. Compare (18a) with (18b), taken from Japanese.

(18a) Daremo naze ko-nak-atta-no?

Anyone why come-NEG-PAST-Q

'Why did no one come?'

Presuppose: No one came.

Not Presuppose: There is a reason that no one came for.

(18b) Daremo nani-o yom-ana-katta-no?

Anyone what-ACC read-NEG-PAST-Q

'What $t_{i}$ did no one read $t_{i}$ ?'

Presuppose: There is something such that no one read it.

Not Presuppose: No one read anything.

To account for the distinctive presuppositional pattern of why-questions in the above, Tomioka formulates the following semantic constraint for why:

(19) Tomioka's constraint:

In a why-question and only in a why-question, the proposition that corresponds to the non-wh portion of the question must be presupposed.

The idiosyncrasies of why discussed so far are compatible with a syntactic proposal by Ko (2005). Ko (2005) puts forward a late merge approach where, in wh-in situ languages (e.g., Japanese, Korean and Chinese), why is merged at $[\mathrm{Spec}, \mathrm{CP}]$ directly, rather than moved to $[\mathrm{Spec}, \mathrm{CP}]$ from a lower position (see also Lin 1992 for an earlier base-generation analysis of Chinese weishenme 'why'). This means that why in these languages has a higher initial position than the other wh-phrases do. In the following, I will adopt Ko's treatment. As such, why does not take part in quantifier scope interactions, because it is directly interpreted at a scope position above quantifier scope. 


\subsection{Witnessable quantifiers license type-e meaning}

In addition to the high scope position of why, I further assume that ccommand relation mirrors scopal relation in the Chinese left periphery. This is because Chinese does not allow scrambling of quantifiers across the directly merged weishenme 'why' (Huang 1982; Ernst 1994; Ko 2005). In Japanese and Korean, scrambled operators reconstruct their scopes at LF, so that when generalized quantifiers are scrambled across the why-adjunct at surface syntax, they receive interpretation at their trace positions (Kitagawa 1990). Importantly, in Chinese it is not possible for generalized quantifiers to ccommand weishenme and still be reconstructed below the scope of weishen$m e$ (and hence receive the GQ-reading). Therefore, c-commanding quantifiers must also take wide scope over weishenme in order to obtain a legitimate interpretation in Chinese. ${ }^{4}$

In the following, I propose that when non-monotone decreasing quantifiers c-command and hence outscope weishenme, they are not GQ-denoting. Specifically, I propose that these quantifiers are type e (individual)-denoting in such cases. Both Reinhart (1997) and Winter (1997) have independently proposed that quantifiers do not necessarily denote a relation between predicates, in the traditional sense of Barwise and Cooper (1981). Rather, they can be referential, by denoting plural indefinites. Following Reinhart's (1997) terms, a quantifier is defined as witnessable if and only if that quantifier receives a plural indefinite reading, denoting its witness set. ${ }^{5}$

(20) A quantifier is witnessable iff it entails the existence of a plurality (a group individual) that satisfies both the quantifier's restrictor and its nuclear scope, i.e., it entails the existence of its witness set.

While largely in keeping with Reinhart's assumptions, I propose to broaden the range of quantifiers that allow for a referential interpretation. In Reinhart's initial classification, only a subset of non-decreasing quantifiers (such as the indefinites a person, several people, some people and many people)

${ }^{4}$ For further discussions on Japanese and Korean scrambling and reconstruction, see Saito (1992), Choe (1994), and Grewendorf and Sabel (1999). For the argument that Chinese does not allow scrambling of generalized quantifiers, see also Soh (1998).

${ }^{5}$ Witness set refers to the plurality individual set determined by the intersection of the restrictor and the nuclear scope. That is, given a quantificational determiner $\mathrm{D}$, one predicate $\mathrm{P}$ and another predicate $\mathrm{Q}, \mathrm{D}(\mathrm{P})(\mathrm{Q})$ gives rise to the witness set $\mathrm{W}=\mathrm{P} \cap \mathrm{Q}$. 
are witnessable. I consider all monotone increasing quantifiers and (nonmonotonic) bare numerals to be witnessable. Thus, I also include quantifiers such as most people, a few people, three people, more than three people, at least three people, etc. In contrast, monotone decreasing quantifiers, such as no/few people and less than three people, are ruled out. I argue that decreasing quantifiers are always GQ-denoting and non-witnessable.

It is worth noting that, for many speakers, decreasing quantifiers such as few tend to favor a reading in which at least one individual satisfies their nuclear scope. We often infer from the utterance Few students arrived that there are at least one student that arrived. However, I believe that the above reading arises as a scalar implicature. This is the view that Horn (2006) holds. Horn correctly points out that the non-empty meaning of decreasing quantifiers is cancelable (one can felicitously utter the following: Few students arrived. In fact, none did). My position, thus, is that monotone decreasing quantifiers' non-empty implicature is not part of the truth-conditional meaning of these quantifiers. Such implicature is different from semantically entailing the existence of witness sets.

Independently, experimental results show that there are processing differences in verifying a quantifier's witness set that depends on its monotonicity (Geurts and van der Slik 2005; Bott et al. 2013). To verify a quantified sentence containing most or more than two, one needs to find positive instances that members within the restrictor set satisfy the most-relation, the more-than-two-relation, etc.. In other words, one has to verify the existence of a witness set. In contrast, for quantified sentences with no, few, or less than two, the verification procedure more often requires drawing a negative inference based on the absence of positive instances (in which case the witness set could be empty). Although there is still a paucity of relevant work on this topic, the intuition is that monotone decreasing quantifiers are not an informative way to denote a witness set.

In what is above, I have pursued the idea that witnessable quantifiers are able to circumvent intervention because they are plural indefinites. Plural indefinites have been known to exhibit exceptional wide scope. To go one step further, I argue that plural indefinites such as most people are topics when they take wide scope over weishenme 'why'. That is, I believe that exceptional wide scope is a topic phenomenon (see also Endriss 2009). A topical reading is possible for quantifiers interpreted as plural indefinites, because all referring expressions that are individual-denoting may serve as topics under the right contextual conditions. Importantly, I argue that topics are able to 
take scope outside of a speech act (that is, they may scope above the illocutionary operator of a sentence). As such, topics scope above the high initial merge position of weishenme in a weishenme-question, since the latter is at [Spec, CP] and scopes under the question operator. As a result, when witnessable quantifiers serve as quantificational topics, no intervention arises. Conversely, I assume that non-witnessable quantifiers cannot be construed as topical, and only a GQ interpretation is available for them. Consequently, non-witnessable quantifiers fail to occur in a wide scope position.

\subsection{Topical quantifiers and speech acts}

In the following, I provide motivations for the claim that topics are able to scope above speech acts. Various authors have pointed out that if any part of a proposition is capable of scoping out of a speech act, it will have to be a topic (Reinhart 1981; Krifka 2001; Ebert et al. 2014). This is because topic establishment is a separate speech act by itself (Krifka further points out that topics even have to scope out of speech acts, given that they function as a separate speech act). The idea that topics are assigned illocutionary operators of their own was first raised in Jacobs (1984). Jacobs points out that introducing a topic is an act of frame setting. As such, it is an initiating speech act that selects an entity, and then requires a subsequent speech act. In the following, I follow Krifka's recent position that natural language allows speech acts to conjoin. A topic-comment structure expresses two sequential, conjoined speech acts, comprising the topic's referring act, to be followed by a basic speech act (assertion, request, command, etc.) that is performed against the referent as established by the topic.

Krifka (2001) notes that, in English, overt devices are used to mark topics as scoping out of questions, commands and curses, such as the following:

(21a) As for Al, Bill and Carl, which dishes did they make?

(21b) The hamburger, please hand it to me.

(21c) This guy, he should go to hell!

Here I follow a long tradition dating back to at least Wittgenstein (1945), in which the speech act of a sentence corresponds to a component of the sentence that combines with the sentence radical. The sentence radical can be seen as unsaturated unless attached to the speech act operator (Åqvist 1975; 
Belnap 1969; Lang and Steinitz 1978; Wachowicz 1978; Chierchia 1993). According to Krifka (2001), speech act operators combine with sentence radical arguments and output speech acts. For instance, the assertion operator ASSERT takes as input a proposition, and returns a speech act. The question operator REQUEST takes as input a set of propositions, and returns a speech act (assuming that a question performs the speech act of a request). To capture topics' referring act, Krifka also posits a referring speech act operator REF, which takes as input a referring expression (type e) and outputs a speech act. Finally, I assume that \& is a conjunction operator that conjoins speech acts. In the case where a sentence in the form of a topic-comment structure performs a question act of request, the request manifests itself in two consecutive speech acts, represented by the following schema:

$$
\begin{aligned}
& \operatorname{REQUEST}\left(<\phi_{\text {topic }}, \psi_{\text {comment }}>\right) \rightarrow \\
& \left.\operatorname{REF}_{X}\left(\phi_{\text {topic }}\right) \& \operatorname{REQUEST}\left(\psi_{\text {comment }}(\mathrm{X})\right)\right)
\end{aligned}
$$

In terms of syntax, Krifka $(1999,2001)$ further proposes that the speech act operator is within the boundary of sentence grammar, occupying a Speech Act Phrase (SAP) projection that is headed by a speech act operator which takes the sentence core (CP) as its complement. Accordingly, we can recursively define two SAPs in the case of topicalization. The topic merges to the specifier of the first SAP, whose head is occupied by another SAP, which is in turn headed by a basic speech act operator taking a CP. For instance, in the why-question (23a), I analyze the DP duoshu ren 'most people' as a topical quantifier. The syntactic representation of (23a) is given in (23b). ${ }^{6}$

(23a) Duoshu ren weishenme cizhi?

most person why resign

'For most people, why did they resign?'

${ }^{6}$ In accordance with my discussions so far, I assume that when referring expressions precede weishenme, they are always topical. An alternative order, in which weishenme takes the sentence-initial position and precedes a referring expression, is always available. In such cases, I assume that weishenme still occupies the $[\mathrm{Spec}, \mathrm{CP}]$ position, and the referring expression takes the IP-internal subject position. (i) illustrates this ordering.

(i) Weishenme ni yao zou?

why you want.to go

'Why do you want to go?' 


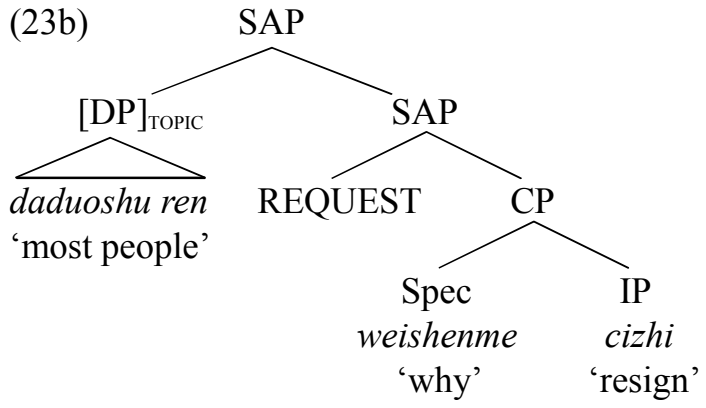

Based on the proposal that a topic act conjoins with a subsequent request speech act performed by a weishenme-question, we would predict that all the expressions that may serve as topics in Chinese may occur outside the scope of weishenme without causing intervention. This prediction is borne out. As (24) demonstrates, proper names, pronouns and temporal/locative adverbs can legitimately c-command weishenme. These are expressions that have long been known to allow for a topic reading (Ernst 1994; Law 2006).

(24a) Zuotian weishenme Lisi mei qu paobu? yesterday why Lisi NEG go jogging 'As for yesterday, as for Lisi, why didn't he go jogging?'

(24b) Zai na'er weishenme dajia xihuan chi kaorou? LOC there why folks enjoy eat barbecued.meat 'Why do the folks there love to eat barbecue?'

Example (25) additionally shows that when multiple topics are co-occurring, they can all c-command weishenme. There seems to be a functionally based cognitive constraint preventing more than three topics from co-occurring in the same sentence in Chinese. Nevertheless, a sentence with three topics is marginally acceptable (Xu 2000). In such case, we also find a weishenmequestion with three c-commanding topics acceptable:

(25) ?Zhe-chang yinyuehui ni mingtian weishenme yao qu? this-CLF concert you tomorrow why want.to go '(As for) This concert, (talking about) tomorrow, why do you want to go?' 
Furthermore, in biscuit conditionals (speech-act conditionals), an if-antecedent may co-occur with a weishenme-question as its consequent, illustrated in (26).

$$
\begin{aligned}
& \text { Ruguo ni bu-jieyi wo wen dehua, ni weishenme cizhi? } \\
& \text { if you NEG-mind I ask PRT you why } \\
& \text { 'If you wouldn't mind me asking you, why did you resign?' }
\end{aligned}
$$

Various proposals have suggested that the antecedents of biscuit conditionals are topics (Endriss and Hinterwimmer 2008; Ebert et al. 2014), which accounts for the fact they scope out of the speech acts performed by the consequents of conditionals. If this is valid, then it is readily predicted by our proposal of topic act that the antecedent in (26) is able to scope above a weishenme-consequent.

Finally, topical expressions may appear outside overt illocutionary markers. In (27), temporal adverbials and proper names may c-command the imperative speech act marker qing (accompanied by a prosodic break).

(27a) Mingtian wanshang, qing zai zheli jihe! tomorrow evening, please LOC here assemble 'At tomorrow morning, please assemble here!'

(27b) Xiaoli, qing zhan chu-lai!

Xiaoli, please step out-DIR

'Xiaoli, step out!'

As (28) demonstrates, witnessable quantifiers in Chinese pattern with other topical expressions and similarly occur to the left of the imperative speech act marker. In contrast, it is unacceptable for a decreasing quantifier to occur in the same sentence-initial position.

(28) $\{$ Shaoshu ren/\#Henshao ren $\}$, qing buyao yingxiang

\{a few person/few person\}, please don't affect

daduoshu ren!

majority.of person

'The minority, please don't affect the majority of us (by making noises, etc.)!'

\footnotetext{
${ }^{7}$ The English translation turns out to be very awkward (which is not the case with the Chinese original). Here shaoshu ren 'a few people' is used as an indefinite, referring to a minority group of people that are identifiable via context, contrary to henshao ren 'few people'.
} 


\section{A semantic account of the intervention pattern}

In this view, if a quantificational element takes wide scope over weishenme, it has to be a topic that scopes outside the weishenme-question's speech act operator. In (29a), the why-question with the quantifier daduoshu ren 'most people' is acceptable, because it receives the interpretation in (29b).

(29a) Daduoshu ren weishenme qu?

most person why go

(29b) Paraphrase:

'(Speaking of/As for) a group individual that has the property of being a majority of all the context-relevant individuals, why did they go?'

On the contrary, why-questions with henshao ren 'few people' are unacceptable, because henshao ren cannot be a topic (whereas shaoshu ren 'a few people' can). That is, (30a) does NOT have the interpretation in (30b).

(30a) \#Henshao ren weishenme qu?

few person why go

(30b) Paraphrase:

\#'(Speaking of/As for) the group individual that has the property of being a minority (less than half) of all the context-relevant individuals, why did they go?'

Furthermore, my theory predicts that bare numerals and monotone increasing modified numerals can be topics. We still need to explain why these numeral quantifiers induce weak intervention, as seen in (31) (repeated from (5)).

?? \{San-ge ren/zhishao san-ge ren/

$\{$ Three-CLF person/at.least three-CLF person/

chaoguo san-ge ren $\} \quad$ weishenme cizhi?

more.than three-CLF person \} why resign

'For \{three people/at least three people/more than three people\}, why did they resign?' 
I believe that the weak acceptability in (31) has a pragmatic reason. Following Kratzer (1998; 2003), I assume that quantificational indefinites receive their values directly from the context of utterance. If the context does not readily offer a particular plurality as the value for the indefinites, the speaker won't know which plurality to pick out with the quantifier, and oddness arises as a result. In the case of numeral quantifiers, we are required to pick out a particular plurality bearing a specific cardinal number, which would leave the hearers with no clues if there is no further information from the context. Krifka (2001: 193) observes the same problem for the English example in (32).

Which dishes did two boys make?

'For two boys that you select: Which dish did they make?'

The acceptability is claimed by Krifka to be marginal. This low acceptability, compared to a definite description, simply follows from the fact that it places a higher requirement on the discourse structure and on hearers' efforts to infer which particular set of two boys are under discussion. This similarly explains why the topical use of quantifiers containing a numeral component is harder. Without explicit contexts providing supporting information, it is not plausible for a naïve hearer to make a partition of the relevant individuals such that one particular individual set of a given cardinality should be distinguished against other individuals.

Finally, embedded questions may offer the contextual information to anchor a particular plurality (Szabolcsi 2010). I will illustrate this with the example in (33).

$$
\begin{aligned}
& \text { (In a report investigating employees' resignation) } \\
& \text { Wo yijing zhidao-le \{chaoguo san-ge ren/ } \\
& \text { I already know-PRF \{more.than three-CLF person/ } \\
& \text { zhishao san-ge ren /san-ge ren\} weishenme cizhi. } \\
& \text { at.least three-CLF person/three-CLF person\} why resign } \\
& \text { 'I already found out for \{more than three people/at least three peo- } \\
& \text { ple/three people\}, why they resigned.' }
\end{aligned}
$$

The indirect question that serves as the complement of found out does not denote a question type, but rather a fact derived from a question. Specifically, the indirect question is construed as a true answer (true resolution) to the corresponding direct question (Ginzburg and Sag 2000; Lahiri 2002). Therefore, 
(33) is paraphrased as follows: 'I already found out (the answer to the question of) for three people, why they resigned'. Following Rooth (2005), this indirect question intuitively answers one subquestion of the overall question: 'Why did a contextually-salient set of individuals resign?' In order to answer this overall question based on the knowledge of the speaker, the question is partitioned into two contrasting subquestions. The first asks about a plurality consisting of three people, of whom the speaker has knowledge about. The other asks about 'the rest of the individuals' of whom the speaker does not provide an answer due to lack of knowledge.

By contrast, monotone decreasing quantifiers cannot be ameliorated in embedded contexts. (34) repeats an example from (8).

$$
\begin{array}{llll}
\text { \#Wo yijing zhidao-le henshao ren weishenme cizhi. } \\
\text { I already know-PRF few person why } & \text { resign } \\
\text { \#'I already knew that for few people, why they resigned.' } &
\end{array}
$$

There is still no way to answer the question of 'for few people, why they resigned?' by providing a particular plurality based on the knowledge state, since there exists no witness set corresponding to the quantifier few. As such, we can explain why monotone decreasing quantifiers consistently induce intervention.

Furthermore, if previous literature (e.g., Partee 1973) is right about the parallelism drawn between quantificational adverbs and quantificational nominal phrases, in that the former quantify over times or possible worlds in the same way as the latter quantify over individual sets, then we should expect that adverbs that are monotone increasing are witnessable, and adverbs that are monotone decreasing are non-witnessable and shall never scope above weishenme (see also Constant 2013: 294). As we already see, the quantificational adverb jingchang 'often' may take wide scope over weishenme when contexts allow speakers to infer a plurality of situations, such that they cover the majority of all the relevant situations. On the other end, contextualization fails to rescue the intervention created by the quantificational adverb henshao 'seldom'.

(35a) Ta jingchang weishenme bei xia-dao?

he often why PASS scare-RES

'For a majority of situations, why was he scared?' 


$$
\begin{aligned}
& \text { \#Ta henshao weishenme bei xia-dao? } \\
& \text { he seldom why PASS scare-RES } \\
& \text { \#'For few occasions, why was he scared?' }
\end{aligned}
$$

Finally, intervention effects induced by focus-sensitive expressions are illustrated as follows (repeated from 12a).

$$
\begin{aligned}
& \text { \#Zhiyou Lisi weishenme cizhi? } \\
& \text { only Lisi why resign } \\
& \text { \#'(As for) only Lisi, why did he resign?' }
\end{aligned}
$$

My current account would predict that if an element is by nature not topical, it will never c-command weishenme. This readily explains the fact that focussensitive expressions, such as only-NPs or even-NPs, cause intervention in weishenme-questions, since they are known to be strongly anti-topical (Tomioka 2007).

\section{Conclusion}

This paper presents a first approximation to a semantic analysis of Chinese intervention effects in why-questions. By investigating the idiosyncrasies of Chinese why-adjunct weishenme, I assume that why does not bind any variable and presupposes a propositional argument. As a consequence, why does not take part in the scopal interaction of the proposition it modifies (in other words, scope-bearing elements within the propositional argument are fully resolved at the scope positions below the position of why). Meanwhile, I assume that topic is interpreted at the widest possible scope in a sentence (Krifka 2001; Ko 2005; Ebert et al. 2014). Topic performs its own speech act of initiating a referent. When topic occurs in a question, the speech act of the topic is conjoined with the question's speech act. Therefore, the scope position of a topic resides outside the illocutionary force of questions. Consequently, if a quantifier is construed as topical, it may scope above weishen$m e$. On the other hand, if a quantifier cannot be construed as topical, it cannot take wide scope, and intervention effects in why-questions arise in such cases. 


\section{References}

Åqvist, L. 1975. "A new approach to the logical theory of interrogatives: Analysis and formalization”. In: Åqvist, L. (ed.), Tubinger Beitrage zur Linguistik. Tübingen: Narr.

Badan, L. 2008. "The even-construction in Mandarin Chinese". In: Djamouri, R., B. Meisterernst and R. Sybesma (eds.), Chinese Linguistics in Leipzig. Paris: EHESS-CRLAO. , 101-116.

Barwise, J. and R. Cooper. 1981. "Generalized quantifiers and natural language". Linguistics and Philosophy 4(2). 159-219.

Beck, S. 2006. "Intervention effects follow from focus interpretation". Natural Language Semantics 14(1). 1-56.

Belnap, N. 1969. "Questions: Their presuppositions, and how they can fail to arise". In: Lambert, K. (ed.), The logical way of doing things. New Haven: Yale University Press. 23-37.

Bott, O., U. Klein and F. Schlotterbeck. 2013. "Witness sets, polarity reversal and the processing of quantified sentences". Proceedings of the 19th Amsterdam Colloquium. 59-66.

Cattell, R. 1978. "On the source of interrogative adverbs". Language 54(1). 61-77.

Cheng, L. and G. Anastasia. 2006. "(In)definiteness, polarity, and the role of whmorphology in free choice". Journal of Semantics 23. 135-183.

Chierchia, G. 1993. "Questions with quantifiers". Natural Language Semantics 1(2). $181-234$.

Choe, H. 1994. "Syntactic wh-movement in Korean and licensing". Theoretical Issues in Korean Linguistics 3. 275-302.

Constant, N. 2013. "Witnessable quantifiers license type-e meaning: Evidence from contrastive topic, equatives and supplements". Semantics and Linguistic Theory 22. 286-306.

Ebert, C., C. Ebert and S. Hinterwimmer. 2014. "A unified analysis of conditionals as topics". Linguistics and Philosophy 37(5). 353-408.

Endriss, C. 2009. Exceptional wide scope. Dordrecht: Springer.

Endriss, C. and S. Hinterwimmer. 2008. "Direct and indirect aboutness topics". Acta Linguistica Hungarica 55(3-4). 297-307.

Ernst, T. 1994. "Conditions on Chinese A-Not-A questions". Journal of East Asian Linguistics 3(3). 241-264.

Geurts, B. and F. van der Slik. 2005. "Monotonicity and processing load". Journal of Semantics 22(1). 97-117.

Ginzburg, J. and I. Sag. 2000. Interrogative investigations. Stanford: CSLI publications.

Grewendorf, G. and J. Sabel. 1999. "Scrambling in German and Japanese: Adjunction versus multiple specifiers". Natural Language and Linguistic Theory 17(1). 1-65.

Heim, I. 1982. The semantics of definite and indefinite noun phrases. (PhD dissertation, University of Massachusetts at Amherst.) 
Heim, I. 1990. "E-type pronouns and donkey anaphora". Linguistics and Philosophy 13(2). 137-77.

Hole, D. 2004. Focus and background marking in Mandarin Chinese. London: Routledge.

Horn, L. 2006. "The border wars: A neo-Gricean perspective". In: von Heusinger, K. and K. Turner (eds.), Where semantics meets pragmatics. Amsterdam: Elsevier. 21-48.

Huang, J. 1982. Logical relations in Chinese and the theory of grammar. (PhD dissertation, MIT.)

Jacobs, J. 1984. "Funktionale Satzperspektive und Illokutionssemantik". Linguistische Berichte 91. 25-58.

Kitagawa, Y. 1990. Anti-scrambling. (Ms., University of Rochester, Rochester, NY.)

Ko, H. 2005. "Syntax of why-in-situ: Merge into [Spec , CP]". Natural Language and Linguistic Theory 23(4). 867-916.

Kratzer, A. 1998. "Scope or pseudoscope? Are there wide-scope indefinites?" In: Rothstein, S. (ed.), Events and grammar. Berlin: Springer. 163-196.

Kratzer, A. 2003. A note on choice functions in context. (Ms., University of Massachusetts at Amherst.)

Krifka, M. 1999. “At least some determiners aren’t determiners”. In: Turner, K. (ed.), The semantics/pragmatics interface from different points of view. Amsterdam: Elsevier. 257-291.

Krifka, M. 2001. "Quantifying into question acts". Natural Language Semantics 9(1). $1-40$.

Kuwabara, K. 1998. "Overt wh-movement and scope-fixing scrambling: A preliminary study". In: Kazuko. I. (ed.), Researching and verifying an advanced theory of human language. Chiban: Kanda University of International Studies. 115-127.

Lahiri, U. 2002. Questions and answers in embedded contexts. Oxford: Oxford University Press.

Law, P. 2006. "Adverbs in A-Not-A questions in Mandarin Chinese". Journal of East Asian Linguistics 15(2). 97-136.

Lawler, J. 1971. “Any questions?” CLS 7. 163-173.

Lin, J. 1992. "The syntax of zenmeyang 'how'and weishenme 'why' in Mandarin Chinese". Journal of East Asian Linguistics 1(3). 293-331.

Oshima, D. 2007. "On factive islands: Pragmatic anomaly vs. pragmatic infelicity". In: Washio, T., K. Satoh, H. Takeda and A. Inokuchi (eds.), New frontiers in artificial intelligence. Berlin: Springer. 147-161.

Partee, B. 1973. "Some structural analogies between tenses and pronouns in English". The Journal of Philosophy 70. 601-609.

Reinhart, T. 1981. "Pragmatics and linguistics: An analysis of sentence topics in pragmatics and philosophy I". Acta Studia Philosophica 27(1). 53-94.

Reinhart, T. 1997. "Quantifier scope : How labor is divided between QR and choice functions". Linguistics and Philosophy 20(4). 335-397.

Rizzi, L. 1990. Relativized minimality. Cambridge, MA: The MIT Press.

Rizzi, L. 2001. "On the position 'Int(errogative)' in the left periphery of the clause". Current Studies in Italian Syntax 14. 267-296. 
Rizzi, L. 2004. "Locality and left periphery". In: Structures and beyond: The cartography of syntactic structures 3. Oxford/New York: Oxford University Press. $223-251$.

Rooth, M. 2005. "Topic accents on quantifiers". In: Carlson, G. and F. Pelletier (eds.), Reference and quantification: The Partee effect. Stanford: CSLI Publications. 303-328.

Saito, M. 1992. "Long distance scrambling in Japanese". Journal of East Asian Linguistics 1(1): 69-118.

Shyu, S. 1995. The syntax of focus and topic in Chinese. (PhD dissertation, University of Southern California.)

Soh, H. 1998. Object scrambling in Chinese. (PhD dissertation, MIT.)

Starke, M. 2001. Move dissolves into Merge: A theory of locality. (PhD dissertation, University of Geneva.)

Szabolcsi, A. 2010. Quantification. Cambridge: Cambridge University Press.

Tomioka, S. 2007. "Pragmatics of LF intervention effects". Journal of Pragmatics 39(9). 1570-1590.

Tomioka, S. 2009. "Why questions, presuppositions, and intervention effects". Journal of East Asian Linguistics 18(4). 253-271.

Westerståhl, D. 2015. “Generalized quantifiers". In: Zalta, E. (ed.), The Stanford encyclopedia of philosophy (Summer 2015 Edition). Available at: $<$ http://plato.stanford.edu/archives/sum2015/entries/generalized-quantifiers/>.

Winter, Y. 1997. "Choice Functions and the Scopal Semantics of Indefinites." Linguistics and Philosophy 20 (4). 399-467.

Xu, L. 2000. "The topic-prominence parameter". ZAS Papers in Linguistics 20. 2141.

Yang, B. 2011. "Intervention effects and wh-construals". Journal of East Asian Linguistics 21(1). 43-87.

\author{
Address for correspondence: \\ Dawei Jin \\ The State University of New York (SUNY) at Buffalo \\ 609 Baldy Hall \\ Buffalo, NY 14260 \\ United States \\ daweijin@buffalo.edu
}

